\title{
ARTICLES
}

\section{ASSESS THE KNOWLEDGE ON PUBERTAL CHANGES AMONG ADOLESCENT GIRLS}

\section{Ms. Leena Mathew (Sr. Gladys Maria)*| Dr. Bimla Rani**}

* Research Scholar, Himalayan University, Itanagar, Arunachal Pradesh \& Asst. Professor, St. John's College of Nursing, Idukki, Kerala, India

** Research Supervisor, Himalayan University, Itanagar, Arunachal Pradesh, India. DOI: http://doi.org/10.47211/trr.2021.v07i01.015

\section{ABSTRACT}

Back ground: Puberty refers to the process of physical changes by which a child's body capable of reproduction and it usually happens in the second decade of life. It is the period of transition from childhood to adulthood. Significant physical and psychological changes take place during these years.(WHO,2006). Objective: To assess the knowledge on pubertal changes among adolescents' girls studying in a selected school at Idukki district. Methodology: A nonexperimental descriptive research design was used for this study. It was conducted in St. George high school Kattappana Idukki district Kerala. The sample consists of 60 adolescent girls who were selected by non-probability convince sampling technique. Self-structured questionnaire was used to assess the knowledge of the adolescent girls. The data were analyzed using descriptive and inferential statistics. Results: Majority of the samples (55.\%) had average knowledge $26.6 \%$ had good knowledge, $16.7 \%$ had poor knowledge and only few $1.7 \%$ sample had excellent knowledge on pubertal changes. It was also observed that a significant association between knowledge and selected demographic variables like seeking help for managing pubertal changes $\left(X^{2}=8.609 p<0.05\right)$, and age of menarche ( $X^{2}$ 9.002, $\left.P<0.05\right)$.

Key Words: Assess, Knowledge, pubertal changes, Adolescent girls, Information booklet

\section{ABOUT AUTHORS:}

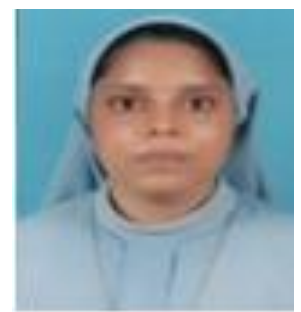

Author Ms. Leena Mathew (Sr. Gladys Maria) is a Research Scholar in Himalayan University at Itanagar in Arunachal Pradesh, India.

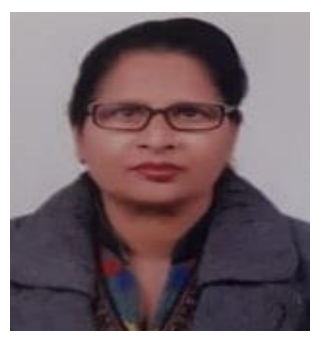

Author Dr. Bimla Rani is a Research Supervisor at Himalayan University in Itanagar, Arunachal Pradesh, India. She has presented papers in various conferences and also has many publications to her name. 


\section{INTRODUCTION}

Adolescence is the period of transition from childhood to adulthood. WHO and UNICEF define adolescents as those aged 10-19 years (WHO 2012; UNICEF 2005). There are many important physical and psychological changes take place during these years. It's usually around the age of 13-19yrs. Adolescents experience rapid physical, cognitive and psychosocial growth. This affects how they feel, think, decisions making, and interact with the world around them (WHO, 2020).Puberty is mainly related to physical growth. In which the immature reproductive system in boys and girls matures and becomes capable of reproduction. Menstruation is the first indication of puberty in girls. During puberty, the physical changes occur which transform the body of child into an adult, changes in body size, and changes in body proportions. In humans, puberty occurs at the onset of adolescence, between the ages of about 11 and 14 in girls and 13 and 16 in boys. (Esther Landhuis, 2020). It is a unique stage of human development and an important time for laying the foundations of good health.

Puberty is the time of conflict; it is the time of life when the child begins to feel liberated, reach sexual maturity and needs guidance. It is the time of contrast because the child shifts between feelings of a being a child and becoming an adult. This is the time they need explanation about the process of puberty that unfolds for everyone and what changes to expect. As most of the pre-adolescent girls are lacking knowledge regarding the pubertal changes and menarche. In order to effectively deal with the transition they require information and a clear picture of their body changes to prevent them from physical problem, guilt and confusion.

\section{NEED FOR THE STUDY}

According to UNICEF ( 2019) adolescents are people those who are in the ages of 10 and 19 and 1.2 billion in the world today, making up 16 per cent of the world's population. One fifth of the world's population is constituted by adolescents (10-19 years) out of which more than 4/5th residing in developing countries. According to world's youth 2013 data sheet, adolescent population of world is 1809.6 million and out of that 367 million_are from India. The adolescents represent about a fifth of India's population that is $22 \%$ of its population. It is expected that this age group will continue to grow reaching over 214 million by 2020. Adolescents aged 10-19 years constitute about one-fourth of India's population and young people aged 10-24 years about one-third of the population. Adolescent girls of 13- 19 yrs. constitute nearly 66 million of population in India. So adolescents are the major chunks of our population.

In puberty, the body goes through a period of rapid growth and sexual development. During this time, adolescents face a number of challenges with regard to their sexual and reproductive health and many problems arise due to the modern lifestyle and risk-taking behavior. When there is lack of knowledge about these changes there will be chance of developing physical, mental and psychological problem and can adversely affect the development and growth of the person. A combination of interventions can help to prevent most of these problems and promote healthy behavior. As a preliminary step the researcher plan to conduct a study on this topic i.e.: assess their knowledge about pubertal changes and in order to increase their knowledge, provide an information booklet.

\section{STATEMENT OF THE PROBLEM}

A study to assess the knowledge on pubertal changes among adolescent girls studying in St. George High School of Kattappana with a view to develop an information booklet.

\section{OBJECTIVES}

- To assess the knowledge on pubertal changes among adolescent girls.

- To find out the association between knowledge on pubertal changes among adolescent girls and selected demographic variables.

- To develop and provide an information booklet about pubertal changes.

\section{RESEARCH METHODOLOGY}

Research Approach: In this study, a quantitative research approach was considered

Research Design: Non experimental descriptive design was used.

Setting: The present study was conducted at St. George High school of Kattappana of Idukki district Kerala.

Sample size: 60 adolescent girls who are aged between $12-14$ years.

Sampling technique: In this study, non-probability convenience sampling technique was used

Data collection tool: Data collection tool was self- structured questionnaire which consist of two parts.

Part-1: Demographic data which consists of age, religion, type of family, previous information, source of information , seeking help for managing pubertal changes age of menarche „, using pain killer during menstruation, protective material during menstruation and parent's education. 


\section{ARTICLES}

Part II: It consists of 25 items of multiple-choice questions to assess the knowledge level of adolescent girls regarding pubertal changes

Data analysis: For data analysis, descriptive and inferential statistics were used.

RESULTS:

SECTION A: It deals with distribution of samples according to demographic variables

\begin{tabular}{|c|c|c|c|}
\hline SL NO & Variables & $\mathbf{F}$ & $\%$ \\
\hline \multirow[t]{4}{*}{1} & Age in years & & \\
\hline & - 12 yrs. & 4 & 6.7 \\
\hline & - 13 yrs. & 2 & 3.3 \\
\hline & - $13 y r s$ & 54 & 90.0 \\
\hline \multirow[t]{4}{*}{2} & Religion & & \\
\hline & - $\quad$ Christian & 31 & 51.7 \\
\hline & - Hindu & 15 & 25.0 \\
\hline & - Muslim & 14 & 23.3 \\
\hline \multirow[t]{3}{*}{3} & Type of family & & \\
\hline & - $\quad$ Nuclear Family & 50 & 83.3 \\
\hline & - Joint Family & 10 & 16.7 \\
\hline \multirow[t]{3}{*}{4} & Any previous information & & \\
\hline & - yes & 56 & 93.3 \\
\hline & - $\quad$ No & 4 & 6.7 \\
\hline \multirow[t]{6}{*}{5} & Source of information & & \\
\hline & - Mother & 52 & 86.7 \\
\hline & - $\quad$ Friends & 2 & 3.3 \\
\hline & - $\quad$ Teacher & 4 & 6.7 \\
\hline & - $\quad$ Social media & 0 & 0 \\
\hline & - $\quad$ Others & 2 & 3.3 \\
\hline \multirow[t]{5}{*}{6} & Seeking help for managing pubertal changes & & \\
\hline & - $\quad$ Mother & 50 & 83.3 \\
\hline & - $\quad$ Father & 0 & 0 \\
\hline & - $\quad$ Peer Group & 8 & 13.3 \\
\hline & - others & 2 & 3.3 \\
\hline \multirow[t]{5}{*}{7} & Age of menarche & & \\
\hline & - $\quad$ Before 10 yrs. & 0 & 0 \\
\hline & - $\quad 10-12$ yrs. & 10 & 16.7 \\
\hline & - $\quad 13-15$ yrs. & 44 & 73.3 \\
\hline & - not yet started & 6 & 10.0 \\
\hline \multirow[t]{4}{*}{8} & Using painkiller during menstruation & & \\
\hline & - Always & 2 & 3.33 \\
\hline & - $\quad$ No & 40 & 66.67 \\
\hline & - $\quad$ sometimes & 18 & 30.0 \\
\hline \multirow[t]{4}{*}{9} & Protective material using menstruation & & \\
\hline & - $\quad$ sanitary pad & 59 & 98.3 \\
\hline & - Cloths & 1 & 1.7 \\
\hline & - Any other & 0 & 0 \\
\hline \multirow[t]{5}{*}{10} & Parent's education & & \\
\hline & - $\quad$ Till $10^{\text {th }}$ & 10 & 16.7 \\
\hline & - $\quad \mathrm{PDC} /$ plus two & 32 & 53.3 \\
\hline & - $\quad$ Graduate & 12 & 20.0 \\
\hline & - $\quad$ Post Graduate / above & 6 & 10.0 \\
\hline
\end{tabular}




\section{ARTICLES}

SECTION-B Distribution of sample according to knowledge level.

Table 2; Frequency distribution of sample according to their level of knowledge

\begin{tabular}{|l|l|l|l|l|}
\hline Knowledge Level & Score & $\begin{array}{l}\text { Score } \\
\text { percentage }\end{array}$ & Frequency & Percentage \\
\hline Excellent & $21-25$ & $81-100$ & 1 & 1.7 \\
\hline Good & $16-20$ & $61-80$ & 16 & 26.6 \\
\hline Average & $10-15$ & $41-60$ & 33 & 55.00 \\
\hline Poor & $0-9$ & $0-40$ & 10 & 16.7 \\
\hline
\end{tabular}

Maximum Score -25

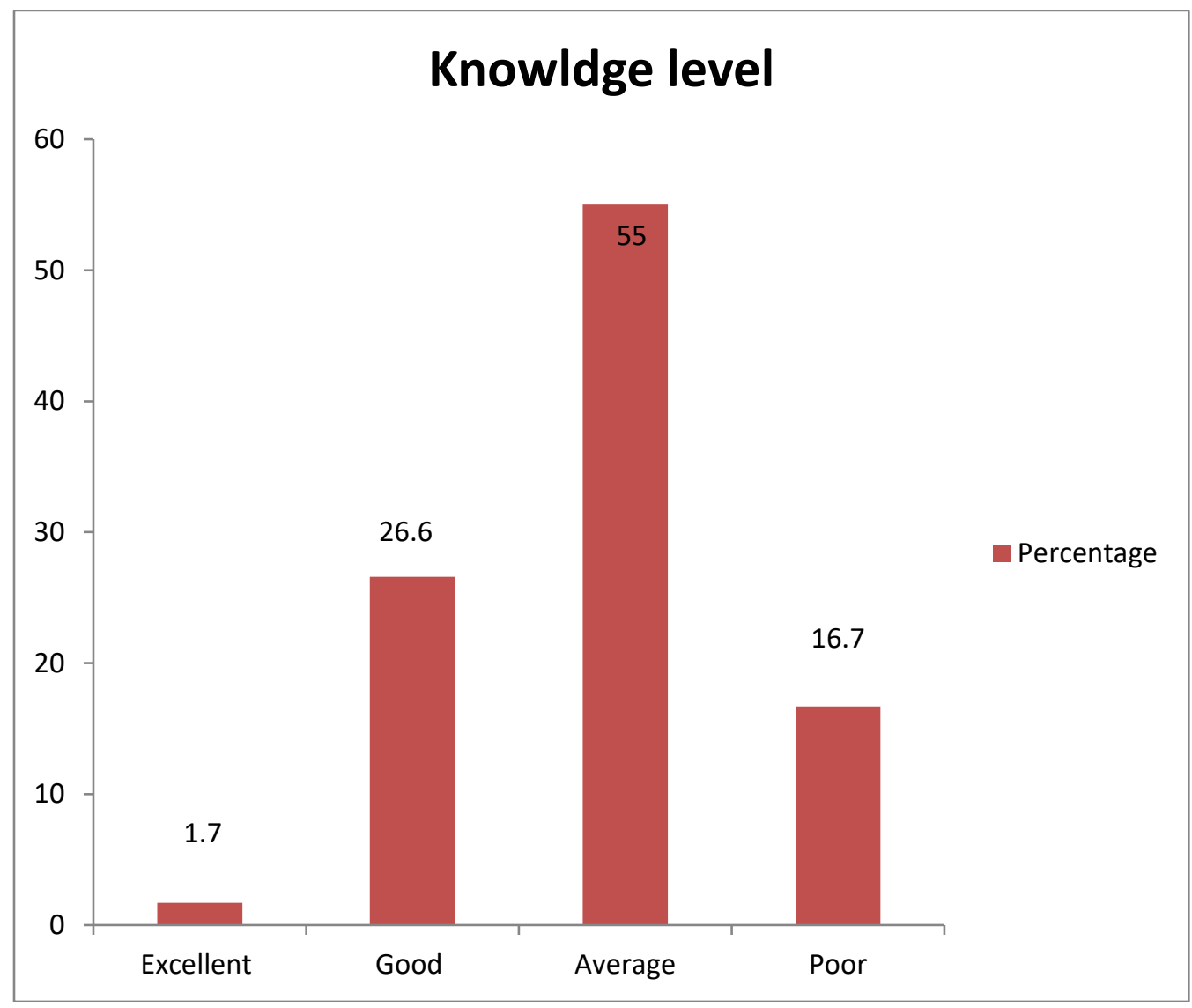

Figure 1: Bar diagram representing distribution of sample according to knowledge level.

Table 2 and Figure 1 bar diagram represents that 1.7. \% sample had excellent knowledge, $26.6 \%$ had good knowledge, 55 . \% had average knowledge and $16.7 \%$ had poor knowledge on pubertal changes. 


\section{ARTICLES}

SECTION C: Association between knowledge level and selected demographic variables.

Table 3: Association of level of knowledge and demographic variables

\begin{tabular}{|l|l|l|l|l|}
\hline S No & variables & $\begin{array}{l}\text { Chi- } \\
\text { square }\end{array}$ & df & p value \\
\hline 1 & Age & 4.469 & 6 & 12.59 \\
\hline 2 & Religion & 3.389 & 6 & 12.59 \\
\hline 3 & Type of family & 1.799 & 3 & 7.82 \\
\hline 4 & Seeking help for managing pubertal changes & 8.609 & 3 & $7.82^{*}$ \\
\hline 5 & Any previous information & 1.180 & 3 & 7.82 \\
\hline 6 & Sources of information & 3.892 & 9 & 16.92 \\
\hline 7 & Age of menarche & 9.002 & 3 & $7.82^{*}$ \\
\hline 8 & Using painkiller during menstruation & 2.804 & 9 & 16.92 \\
\hline 10 & Protective material using menstruation & 5.085 & 3 & 7.82 \\
\hline
\end{tabular}

$\mathrm{P}<0.05$

* Significant

\section{DISCUSSION}

Part I: Distribution of samples based on demographic data

Demographic variables selected for this study were age, religion, type of family, previous information, source of information, age of menarche, seeking help for managing pubertal changes, using pain killer during menstruation, protective material during menstruation and parent's education. Result showed that most of the samples $90 \%$ (54) had 13 years old. More than half 51\% (31) samples belong to Christian religion. Majority $83.3 \%$ (50) adolescent girls from nuclear family. All most all the samples $93.3 \%(56)$ had previous information about pubertal changes. 86.7 (52) adolescent girls got the knowledge about pubertal changes from their mothers. Seeking help for managing pubertal changes, majority $83.3 \%$ (50)adolescent girls received from their mothers only. More than half of them $73.3 \%(44)$ attained their menarche at the age between $13-15$ years. Majority of the samples $66.67 \%$ (40) were not using any pain killer during menstruation. All most all the samples $98.3 \%$ (59) were using sanitary pad for the protection. 53.3\% (32) adolescent girl's parents had PDC/Plus two educations.

Some of these findings were consistent with another study carried out in Mangalore (Diana SRA) reported that majority of the subjects (86\%) were in the age group of 13-14 years and most of the subjects were from nuclear family (74\%), which is supporting to the present study. It also revealed that majority of the subjects were Hindu (78\%), $10 \%$ were Muslim and $12 \%$ were Christian religion. But the present study reported that more than half of them $51 \%$ (31) samples belong to Christian religion,25\% (16)belong to Hindu religion and $23 \%(14)$ from Muslim religion. Another study conducted in Nepal which result showed that parent's education, seeking help for pubertal changes were similar to the present study; 93.17\% mothers and almost all (99.51\%) fathers were literate and most of the adolescent girls seek help from mothers. However, regarding source of information, is contradicting to the Nepal study; main source of information regarding pubertal changes of adolescent girls were friends, followed by mothers in that study (P Sandhya, 2017). Present study revealed that majority of the sample 98.3\% were using sanitary pad and $73.3 \%$ attained their menarche between the age of $13-15$ yrs. Similar finding also observed in another study in which, 95.5\% using sanitary pads. Majority of the samples, $90.8 \%$ attained their menarche between 11-13 years.(Veena KR Bhagavan2019).

Part II : Level of knowledge on pubertal changes

The present study report revealed that majority of the samples $55 \%$ had average knowledge $26.6 \%$ had good knowledge, $16.7 \%$ had poor knowledge and only few $1.7 \%$ sample had excellent knowledge, on pubertal changes. 


\section{ARTICLES}

A similar study conducted in Tamilnadu (J L Prasad 2020) results showed that $33 \%$ adolescent girls were having moderately adequate knowledge whereas $6 \%$ of adolescent girls were having inadequate knowledge. Only few of them had (11\%) adequate knowledge. A descriptive study conducted in Ludhiana, Punjab ( M Kaur, 2018) also revealed that $82 \%$ of adolescent girls had average knowledge, followed by $13 \%$ had good knowledge and few of them (5\%) had below average knowledge on pubertal changes. Similarly, the above Nepal study ( P Sandhya, 2017), findings showed that $16 \%$ adolescents had very good level of awareness, $47 \%$ had good level of awareness, $28 \%$ had average level of awareness and $9 \%$ had below average level of awareness regarding pubertal changes This also congruent to the present study, whereas another cross sectional study conducted in Karaj, Iran (M Farid, 2019) contradicting to the present study as it showed, high majority $(85.1 \%)$ of the participants had high knowledge about pubertal changes.

\section{Part III: Association between level of knowledge and demographic variables}

The present study showed that there was significant association of knowledge and selected demographic variables like seeking help for managing pubertal changes $\left(X^{2}=8.609 p<0.05\right)$, and age of menarche $\left(X^{2} 9.002, P<\right.$ 0.05). However other variables had no association.

\section{CONCLUSION}

The present study was conducted to assess the knowledge on pubertal changes among adolescent girls. Result revealed that majority of the samples (55. \%) had average knowledge about pubertal changes and only very few $(1.7 \%)$ of them had excellent knowledge. It shows still there is a gap in information related to pubertal changes. This indicates the importance of conducting a training program to increase the level of awareness among the adolescent girls. So, the researcher developed and provided an informational booklet regarding pubertal changes.

\section{REFERENCES}

1. Dhakal B. (2020) Knowledge and Attitude Regarding Pubertal Health among Adolescent Girls. Nepal Health Res Counc. 2020 Jan 21;17(4):437-442. doi: 10.33314 /jnhrc. v1 7i4.1559. PMID: 32001845.

2. J L Prasad et al, (2020). A Study to assess the knowledge on pubertal changes and menarche among adolescent girls residing in as selected rural community, Kanchipuram District, Tamilnadu. Medico Legal Update, 20(3), 102-104. https:/ /doi.org/ 10. 37506 /mlu.v20i3.1376

3. Farid M, Barandouzi ZA, Vallipour NS Knowledge, attitude and coping strategies regarding pubertal changes among adolescent girls: Risk and compliances for health promotion in puberty J Edu Health Promot1019:8: 176.

4. Anusha G P et al (2019)To study the effect of health education on knowledge of pubertal changes and menstrual hygiene, Journal of Clinical Obstetrics and Gynecology 2019;3(2): 79-82.

5. Manjot Kaur( 2018) A descriptive study to assess the knowledge on pubertal changes during adolescence among the adolescent girls studying in selected school of district Ludhiana,Punjab.http://nursing.journalspub.info/index.php?journal=ijwhn\&page=article\&op=view\&path $\% 5 B \% 5 D=481$

6. Manisha Rani RN, Sheoran P, Yogesh Kumar RN, Singh N.( 2016) Evaluating the Effectiveness of Pubertal Preparedness Program in Terms of Knowledge and Attitude Regarding Pubertal Changes Among PreAdolescent Girls. J Fam Reprod Health 2016; 10(3): 122-128

7. Phillips-Howard PA, Caruso B, Torondel B, et al. Menstrual hygiene management among adolescent schoolgirls in low- and middle-income countries: research priorities. Glob Health Action. 2016; 9:38.

8. C Sivagurunathan, R. Umadevi,R. Rama, and S. Gopalakrishnan Adolescent Health: Present Status and Its Related Programmes in India. Are we in the right direction Published online 2015 Mar 1. doi: $10.7860 / J C D R / 2015 / 11199.5649$

9. Journal of international oral health international society of preventive and community density, 2015 feb; 7(2): $1-5$.

10. The journal of Nursing research INR volume 23, no.3, September 2015 , page no. 236 